\section{AN INHIBITOR FOR INOSITOL- SPECIFIC PHOSPHOLIPASE C FROM Actinomadura sp.}

Hiroshi Ogawara, Kyolchiro Higashi, Shigeru Manita, Koutchi Tanaka ${ }^{\dagger}$, Yasuyo Shimizu ${ }^{\dagger}$ and Liang Shufang ${ }^{\dagger \dagger}$

Department of Biochemistry, Meiji College of Pharmacy, Nozawa-1, Setagaya-ku, Tokyo 154, Japan

${ }^{\dagger}$ Central Research Laboratories, Yamanouchi Pharmaceutical Company, Ltd., Azusawa-1, Itabashi-ku, Tokyo 174, Japan

"Shanghai Institute of Materia Medica, Academia Sinica, 319, Yue-Yang Road, Shanghai 200031, China

(Received for publication February 13, 1992)

Inositol-specific phospholipase $\mathrm{C}$ catalyzes the hydrolysis of phosphatidylinositol 4,5-bisphosphate to generate inositol 1,4,5-trisphosphate and diacylglycerol. These two compounds, in turn, serve as intracellular second messengers ${ }^{1)}$. Inositol-specific phospholipase $\mathrm{C}$, therefore, plays an important role in the signal transduction pathway of various systems. Thus, an inhibitor of phospholipase C would be a possible candidate for cancer chemotherapy and also a hopeful reagent to explore the mechanism of the signal transduction in these systems. In this line of screening program, we isolated Q12713 substance from fermentation broth of Actinomadura sp. This report describes the isolation of Q12713 substance from Actinomadura sp., which is an inhibitor of inositol-specific phospholipase $\mathrm{C}$.

The microorganism producing the inhibitor was isolated from a soil sample. Based on the cultural and physiological properties, strain Q12713 was identified as Actinomadura sp.

Phospholipase $\mathrm{C}$ activity of bovine brain was determined in a final volume of $50 \mu \mathrm{l}$ containing [inositol- $\left.2-{ }^{3} \mathrm{H}(\mathrm{N})\right]$ phosphatidylinositol 4,5 -bisphosphate $(0.2 \mu \mathrm{Ci} / \mathrm{ml}, 38 \mathrm{~nm}), 0.8 \mathrm{mg} / \mathrm{ml}$ phosphatidylcholine, $0.1 \mathrm{M}$ HEPES- $\mathrm{NaOH}$ pH $7.0,1 \%$ sodium cholate, $1 \mathrm{~mm} \mathrm{MgCl}_{2}, 1 \mathrm{~mm} \mathrm{CaCl}, 0.1 \%$ bovine serum albumin, $1 \mathrm{~mm}$ dithiothreitol, $50 \mathrm{~mm}$ $\mathrm{KCl}$, partially purified bovine brain phospholipase $\mathrm{C}$ and the inhibitor. After 15 minutes at $37^{\circ} \mathrm{C}$, the reaction was terminated by the addition of $200 \mu 1$ of $10 \%$ trichloroacetic acid and kept at $4^{\circ} \mathrm{C}$ for 30 minutes. Then the reaction mixture was centrifuged for 5 minutes at $16,000 \mathrm{rpm}$ and the radioactivity in the supernatant was measured by a liquid scintillation counter. The inhibitory activity was calculated from the remaining phospholipase $C$ activity as follows: $(a-b) /(a-c) \times 100$, here ' $a$ ' is the radioactivity of a sample without an inhibitor; ' $b$ ' is the radioactivity of a sample with an inhibitor; and ' $c$ ' is the radioactivity of a sample without the enzyme.

A loopful of cells of the strain Q12713 from an agar slant was inoculated into a 500-ml Erlenmeyer flask containing $100 \mathrm{ml}$ of a medium composed of potato starch $1 \%$, Polypepton $1 \%$, roast wheat germ $0.5 \%$, copra meal $1.0 \%$, carrot meal $0.5 \%$ and $\mathrm{CaCO}_{3} 0.15 \%$. The $\mathrm{pH}$ was adjusted to 7.0 before sterilization. The flasks were incubated in a rotary shaker at $28^{\circ} \mathrm{C}$ for 120 hours at $220 \mathrm{rpm}$.

The purification procedure outlined in Fig. 1 yielded $A$ and $B$ substances as inositol-specific phospholipase $\mathrm{C}$ inhibitors. Whole fermentation broth (5 liters) was extracted with 4 liters of ethyl acetate twice, and the solvent phases were combined and evaporated to dryness under reduced pressure. The solid thus obtained was dissolved in ethyl acetate and purified by preparative thin-layer chromatography on silica gel plates followed by silica gel column chromatography and preparative thin-layer chromatography on $0.5 \mathrm{M} \mathrm{NaH} \mathrm{NO}_{4}$ treated silica gel plates. Then, the active fraction was

Fig. 1. Purification procedure of Q12713 substance.

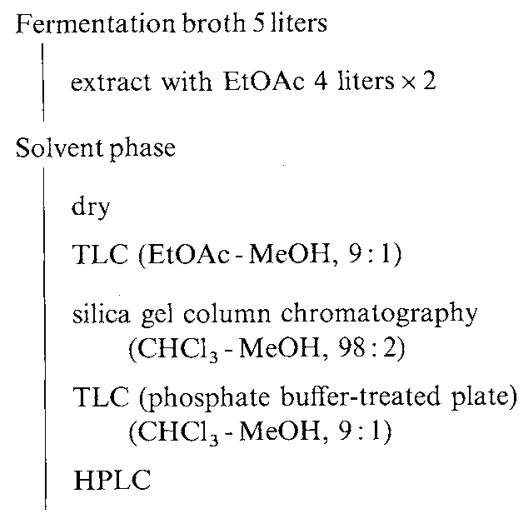

White powder (A: $0.15 \mathrm{mg}, \mathrm{B}: 2.1 \mathrm{mg}$ ) 
dissolved in methanol and the solution was applied to a $20 \mathrm{~mm} \times 250 \mathrm{~mm}$ Inertsil prepODS column and developed with $80 \%$ acetonitrile. $A$ and $B$ substances were obtained at retention times of 9.968 and 12.405 minutes, respectively. The melting point of $\mathrm{B}$ substance was 152 to $156^{\circ} \mathrm{C}$ and $[\alpha]_{\mathrm{D}}^{20}$ was $-49.7^{\circ}$ (c 0.1 , methanol). RYdon-SMITH reaction was positive but ninhydrin, anthrone and SAKAGUCHI reactions were negative. When the isolated $B$ substance was injected to a column of HPLC, B as well as A substances were detected in the eluants. On the other hand, when the isolated A substance was injected to a column of HPLC, A as well as B substances were eluted. It is concluded, therefore, that A substance was in an equilibrium with $\mathrm{B}$ substance. The ${ }^{3} \mathrm{H}$ and ${ }^{13} \mathrm{C}$ NMR spectra, IR spectrum and the mass spectrum of $\mathrm{B}$ substance indicated that they were very similar to those of $\mathrm{MH} 755-\mathrm{CF}^{2)}$ and $\mathrm{BU}-3983 \mathrm{~T}^{3)}$. The direct comparison with these substances by HPLC confirmed that these three compounds were identical. These two compounds were isolated as cytotoxic substances against tumor cells.

Q12713 substance showed $\mathrm{IC}_{50}$ for inositolspecific phospholipase $\mathrm{C}$ from bovine brain at $8.5 \times 10^{-6} \mathrm{M}$, and $\mathrm{Ki}$ of $2.6 \times 10^{-5} \mathrm{M}$ in a competitive manner with the substrate. However, it showed no inhibitory activity against phospholipase $\mathrm{C}$ from Bacillus cereus. This enzyme is rather specific for lecithin. Only one compound named vinaxanthone was isolated as a phospholipase $\mathrm{C}$ inhibitor so $\mathrm{far}^{4}$. However, detailed report on its activity has not been published. Therefore, Q12713 substance should be a useful reagent for the analysis of the mechanism of signal transduction and might be a helpful drug for cancer and other diseases in which the signal transduction works.

\section{Acknowledgment}

We are grateful to T. TAKEUCH of the Institute of Microbial Chemistry and T. OKI of the Bristol-Myers Squibb Co., Ltd. for their kind gifts of MH755-CF2 and BU-3983T, respectively.

This work is supported in part by the Grant-in-Aid for cancer research from the Ministry of Education, Science and Culture, Japan.

\section{References}

1) RHEE, S. G.: Inositol phospholipid-specific phospholipase $\mathrm{C}$ : interaction of the $\gamma_{1}$ isoform with tyrosine kinase. Trends Biochem. Sci. 16: $297 \sim 301$, 1991

2) Takeuchl, T.; M. Hamada, H. Naganawa, M. Ishizuka, M. Inima \& $\mathrm{H}$. Suda (Institute of Microbial Chemistry): A new antibiotic MH755CF2. Jpn. Pat. 128791 ('89), Nov. 16, 1987

3) Sugawara, T.; Y. Nishiyama \& H. Yamamoto (Bristol-Myers Squibb): An antitumor antibiotic BU-3983T. Jpn. Pat. 218394 ('91), Nov. 5, 1990

4) Aoki, M.; Y. Itezono, H. Shirai, N. Nakayama, A. Sakai, Y. Tanaka, A. Yamaguchi, N. Simma, K. YoKose \& H. SETo: Structure of a novel phospholipase C inhibitor vinaxanthone (Ro 09-1450), produced by Penicillium vinaceum. Tetrahedron Lett. 32: $4737 \sim 4740,1991$ 